\title{
COMO PENSAR A LIBERDADE A PARTIR DA SUBSTITUIÇÃO?
}

\author{
HOW TO THINK FREEDOM FROM SUBSTITUTION?
}

Diogo Villas Bôas Aguiar*

\section{RESUMO}

Outramente que ser (Autrement qu'être ou au-delà de l'essence) estabelece uma diferença fundamental e pontua uma ruptura com Totalidade e infinito no que diz respeito ao modo como a subjetividade é interpretada. Trata-se da noção central de substituição. Este não é, de modo algum, um conceito de fácil apreensão, e não encontramos no texto levinasiano uma formulação explícita daquilo que significaria substituir-se. No entanto, adotaremos aqui uma estratégia que nos permitirá uma aproximação que, em nosso modo de ver, torna possível uma forma interessante de abordar esse tema. A substituição traz consigo, de imediato, o problema da liberdade. Tendo em vista a sempre recorrente, e não menos problemática, discussão entre passividade e atividade, o que significaria pensar a liberdade a partir da substituição? Se substituir-se não se origina de um ato de liberdade do sujeito, deliberando para si mesmo a decisão de sacrificar-se por outrem, o que seria tal substituição e qual o sentido de ainda falarmos em liberdade nesse contexto? Buscaremos defender que o conceito levinasiano de substituição deve ser pensado em conjunto com o de liberdade, pois a liberdade é simultaneamente derivação da heteronomia e origem da possibilidade de toda ação.

PALAVRAS-CHAVE: Liberdade. Substituição. Heteronomia.

\section{ABSTRACT}

Otherwise than being establishes a fundamental difference and states a rupture with Totality and Infinity regarding how the subjectivity is interpreted. This is the central idea of substitution. This is in no way a concept easy to grasp, and we do not find in the text an explicit formulation of what it would mean to substitute oneself. However, we will adopt here a strategy that will allow an approximation in which, in our view, makes possible an interesting way to approach this issue. Substitution carries with it, right away, the problem of freedom. Given the ever-recurring, but not least problematic discussion between passivity and

\footnotetext{
*Doutorando em Filosofia pela Universidade Federal de Santa Maria. E-MAIL: villasboas.diogo@outlook.com.
} 
activity, what would mean to think freedom from substitution? If substitution does not originate from an act of freedom of the subject, deliberating for itself the decision to sacrifice itself for others, what would be such substitution and what is the point of even speak about freedom in this context? We will try to defend that we must think substitution and freedom together, because freedom is both derivation of heteronomy and origin of the possibility of all action.

KEYWORDS: Freedom. Substitution. Heteronomy.

\section{O PROBLEMA DA LIBERDADE, O PROBLEMA DA SUBJETIVIDADE}

Dois conceitos, dois problemas. Mas não só, não se trata de quaisquer conceitos. Lidar com o problema da liberdade e da subjetividade implica arcar com toda uma tradição moderna de discussão, envolvendo vários pensadores, cada qual com suas nuanças. A subjetividade demarca o modus operandi filosófico moderno. A esse conceito foi designada a função central de fundamentar tanto o conhecimento, quanto a moralidade. Podemos pensar, emblematicamente, no recurso cartesiano de uma recondução à autodeterminação e autoexperiência do cogito. Ou, ainda, o caso de Kant, em que fica explícito o vínculo necessário que deve haver entre a subjetividade moral e a autonomia, a liberdade em sentido prático. Mais ainda, lidar com esses conceitos implica, simultaneamente, lidar - criticamente - com uma concepção de homem. Evidentemente, riscos de generalizações são iminentes. No entanto, ver a modernidade desde essa perspectiva nos permite fincar um ponto de contraposição em relação a Levinas. Apesar de ainda utilizar os mesmos termos - sujeito e liberdade - não se trata de modo algum dos termos modernos. Quando Levinas fala em subjetividade e em liberdade não é a modernidade que está por trás; antes, é o horizonte aberto pelos aportes husserlianos e heideggerianos através da fenomenologia, em uma relação difícil e ambígua, uma vez que é ao mesmo tempo proximidade e distância em relação a ambos. Justamente por isso, é preciso fazer um esforço interpretativo que vise delinear a fronteira entre o sujeito moderno e o sujeito levinasiano, entre a liberdade moderna e a liberdade levinasiana, explicitando como a subjetividade pode ser entendida em termos de uma irredutibilidade ao saber e ao ser e sua consequência imediata para pensar a liberdade ${ }^{1}$.

\footnotetext{
${ }^{1}$ Apesar de escassa, há uma bibliografia concernente ao tema da liberdade na obra de Levinas. Destacamos os seguintes textos: Atterton (2001), Calin (2005) e Pérez (2006). A nossa dissertação de mestrado, da qual este artigo representa uma revisitação do terceiro capítulo, também propõe uma reflexão sobre essa temática (AGUIAR, 2014). Sobre o modo como Levinas faz uso da fenomenologia husserliana para desenvolver o
} 
Estruturamos este artigo desde uma dinâmica interna que é motivada a partir de três questionamentos. O primeiro deles situa, do ponto de vista textual, o locus da discussão que trazemos no contexto da obra levinasiana: Autrement qu'être ou au-delà de l'essence

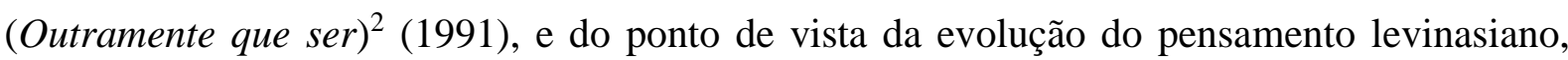
fornece a motivação fundamental da elaboração deste texto. Uma vez explicitada sua motivação, o segundo questionamento avança na discussão ao pontuar uma diferença fundamental em relação à obra anterior, Totalidade $e$ infinito ${ }^{3}$ (LEVINAS, 2008), opondo hospitalidade e substituição ${ }^{4}$. Introduzimos, portanto, o problema da subjetividade em Outramente que ser. O terceiro e último questionamento perspectiva o problema da substituição a partir de sua relação com o conceito de liberdade, articulando, portanto, nosso objetivo final: fornecer elementos que esclarecem, minimamente, como é possível pensar a liberdade a partir da substituição.

\section{POR QUE OUTRAMENTE QUE SER?}

Dar conta de qualquer tema abordado em Outramente que ser exige daquele que o pretende fazer, se tiver como horizonte compreender a própria dinâmica da evolução do pensamento levinasiano, lidar minimamente com aspectos que fornecem chaves elucidativas para o entendimento do texto em questão. Por isso, considero importante trazer de início um ponto que indicaria uma resposta possível para a seguinte questão: por que Levinas escreveu Outramente que ser? Tal pergunta se justifica pelo fato de que esse livro não versa sobre uma problemática estranha, por exemplo, a de Totalidade e infinito. Há uma intuição fundamental que singulariza e está presente nos textos levinasianos: a tese da ética como filosofia primeira. Nesse sentido, Outramente que ser se apresenta muito mais em termos de uma reformulação argumentativa que embasaria e reforçaria essa tese do que uma contraposição ou negação. Há, por isso, um caminho que vai de Totalidade e infinito à Outramente que ser. Damos-nos por satisfeitos aqui, em termos introdutórios, de apenas apontar para aquela que nos parece ser a resposta para a pergunta sobre a motivação da sua elaboração.

outramente que ser, remetemos às considerações feitas pelo professor Marcelo Fabri em artigo no qual propõe uma reflexão sobre o tema de uma negação originária em que há um psiquismo irredutível que não é uma modalidade de ser, mas outramente que ser (FABRI, 2010).

${ }^{2}$ Utilizaremos o título traduzido para o português. Entretanto, para fins de citação e referência, indicaremos AE para nos referir a essa obra, considerando o título em francês: Autrement qu'être ou au-delà de l'essence.

${ }^{3}$ Faremos uso da abreviação TI para nos referir a esse texto.

${ }^{4}$ Sobre esse conceito em específico, ver Bernasconi (2006) e Maloney (1997). 
A tese da ética como filosofia primeira, ou, se se quiser, do problema da explicitação sobre como é possível pensar a ética sem ontologia, exigiu de Levinas, em um primeiro momento, a afirmação radical da separação da alteridade. No entanto, comportou uma crítica muito bem elaborada por Derrida (2011) em Violência e metafísica. Em última instância, mostrou-se, no texto supracitado, que Totalidade e infinito recai em um paradoxo: como enunciar a transcendência sem que se exija da linguagem mais do que ela pode nos oferecer. A acusação consiste no fato de que Totalidade e infinito anuncia o primado da ética, mas o faz a partir da utilização de uma linguagem que é ontológica. Esse seria, portanto, segundo Derrida, o alto preço a ser pago se se pretender defender a tese levinasiana. Nesse sentido, ao ser confrontado com essa dificuldade, Outramente que ser representa um ponto de inflexão que se faz desde uma superação linguístico-metodológica. O paradoxo de Totalidade $e$ infinito, no entanto, não é anulado, mas adquire uma centralidade que permanece no desafio de enunciar o Outramente.

Do ponto de vista metodológico, a novidade fica por conta do que Levinas denominou de procedimento enfático. Contrapondo-se aqui ao que seria claramente uma investigação fenomenológica transcendental que buscaria pela origem $^{5}$, a consequência desse modo de proceder reside no próprio modo de justificação de uma ideia. Ao não ir mais em busca do originário, parte-se em direção ao superlativo ou à situação limite do próprio fenômeno. Ora, tal situação limite requer, ainda, uma superação da ontologia desde o que Levinas chama de uma filosofia do desdizer. A saída é manter-se na tensão da ambiguidade da diferença entre o Dizer e o Dito. Uma vez que o caráter denotativo/descritivo pertence ao âmbito da ontologia portanto, do Dito -, é ao Dizer que cabe a função de preservar a necessidade da sempre retomada atividade de Desdizer o Dito, evitando a tendência de engessamento da transcendência. É a partir da conjugação dessa superação, que é simultaneamente metodológica e linguística, que a estruturação do Outramente é erguida.

\footnotetext{
${ }^{5}$ Suscitamos aqui uma problemática que não constitui de modo algum ponto pacífico na interpretação dos textos de Levinas. Como já dissemos antes, a relação de Levinas com a fenomenologia é ambígua. Não há dúvidas de que ela teve um papel central no desenvolvimento dos seus textos. No entanto, ainda que algo que mereceria um tratamento mais acurado e extenso - trabalho que só diz respeito tangencialmente ao nosso objetivo neste artigo -, gostaríamos apenas de deixar em aberto a pergunta sobre até que ponto Outramente que ser - enfatizamos: não toda a obra de Levinas, mas esse texto tardio especificamente - do ponto de vista metodológico, pode ou não ser caracterizado como fenomenologia.
} 


\section{SE NÃO SE TRATA MAIS DE HOSPITALIDADE, O QUE SIGNIFICA SUBSTITUIÇÃO?}

Esse novo procedimento característico de Outramente que ser fornece a possibilidade de atingir uma outra maneira de abordar a subjetividade. Há dois enunciados que gostaríamos de evocar por julgar ser ilustrativo para nosso propósito, já que se lidos paralelamente, podem nos fornecer, de imediato, a diferença entre Totalidade e infinito e Outramente que ser. No primeiro, lemos: "Este livro apresenta-se, pois, como uma defesa da subjetividade [...] fundada na ideia de infinito" (TI, p. 12). Já no segundo, "Este livro interpreta o sujeito como refém e a subjetividade do sujeito como substituição" (AE, p. 232, tradução nossa). Essas duas passagens pontuam a diferença no modo como a subjetividade é interpretada: não é mais fundada na ideia de infinito - entenda-se, acolhendo a ideia de infinito, hospitalidade -, mas como substituição. Desse modo, se a dinâmica interna de Totalidade e infinito sustentava a forte oposição entre interioridade e exterioridade, definindo a subjetividade em termos de hospitalidade, o método enfático aponta para superlativação da subjetividade como substituição. Evidentemente, a discussão passa necessariamente por uma reflexão sobre o si mesmo, e ganha significação a partir do uso da metáfora presente na narração mítica da túnica de $\mathrm{Nesso}^{6}$.

Em linhas gerais, tal túnica, embebida de um veneno, consome a carne daquele que a veste de tal modo que só seria possível pôr um fim ao tormento que causa mediante a perda de sua própria integridade. Assim é a subjetividade levinasiana, exposta de tal modo à alteridade que na própria ênfase dessa exposição descobre-se sublimada como resposta - trata-se do outro-na-minha-pele, expresso pela própria ideia de perseguição. Nesse sentido, a presença do outro é tão intensa que provoca um descentramento da ipseidade e diz o si mesmo já como alteridade - expulso de si, apesar de si. É a ideia de passividade que incide aqui, ou da passividade mais passiva que toda passividade, precisamente porque não se confunde com a concepção clássica que a opõe à atividade. A passividade em sentido levinasiano não serve como suposto para uma atividade que viria posteriormente. Ela é precisamente a impossibilidade de evadir-se da exposição sempre contínua ao outro, sendo, por isso mesmo, aquilo que não quis, sequer escolhi, e tampouco poderia querer ou escolher. Chegamos, assim, a uma formulação rudimentar daquilo que pode significar substituição: o si mesmo é a tal

\footnotetext{
${ }^{6}$ Sobre esse tema, ver Berckert (2006).
} 
ponto já marcado pela alteridade que, expulso de si, substitui-se, invertendo-se a própria identidade - eu é um outro.

\section{EM QUE CONSISTE A LIBERDADE NO CONTEXTO DA SUBSTITUIÇÃO?}

O impasse é claro. Há uma alteridade na gestação do si-mesmo. No entanto, disso, afirma Levinas, não decorre uma alienação que o tornaria escravo. Ser si-mesmo, ainda que marcado pelo outro, não significa que agora temos o inverso da liberdade: escravidão. É legítimo questionar Levinas nesse ponto. Ora, como é possível ser si-mesmo se a alteridade já me expulsa de mim? Como isso não se confunde com alienação? E a liberdade, como podemos dizer que ela ainda existe nessas condições? “[...] não é como liberdade [...] que a subjetividade se impõe como absoluta. [...] Paradoxalmente, é enquanto alienus - estrangeiro e outro - que o homem não é alienado" (AE, p. 76, tradução nossa). A via pela qual podemos encontrar uma maneira de amenizar esse problema recorre à noção de inspiração, ainda que sua inserção em um contexto ético, em vez de estético, não seja óbvia. ${ }^{7}$ A oposição entre ética e estética a partir da caracterização da primeira como aquela que pertence ao campo da intenção e da segunda, ao campo da inspiração, exige que façamos alguns esclarecimentos.

A inversão entre inspiração e intenção poderia levantar a questão sobre a impessoalidade da inspiração, sobretudo se levarmos em consideração a origem grega, segundo a qual a inspiração adviria das musas que ditavam seu canto. No entanto, quando falamos em inspiração ética, não dizemos strictu sensu a mesma coisa que inspiração estética. A inspiração ética é responsável pela individuação do eu a partir da escuta de uma voz que comanda. Assim, ao delicado tema da inspiração, sempre vem um segundo associado, que é o da obediência.

\footnotetext{
Nessa substituição em que a identidade se inverte, nessa passividade mais passiva que a passividade conjunta do ato, além da passividade inerte do designado, o si absolve-se de si. Liberdade? Liberdade outra que aquela da iniciativa. Pela substituição aos outros, o Si-mesmo escapa à relação. [...] Nessa passividade, a mais passiva, o si liberta-se eticamente de todo outro e de si. Sua responsabilidade pelo outro - a proximidade do próximo não significa a submissão ao não-eu, ela significa uma abertura em que a essência do ser excede-se na inspiração [...] (AE, p. 146, tradução e grifos nossos).
}

\footnotetext{
${ }^{7}$ Estamos consoante as sugestões de Calin (2005).
} 
Exceder a essência do ser pela inspiração da obediência a outrem, eis a tese que sustenta fundamentalmente a noção levinasiana de liberdade. A problemática aqui se assemelha ao mesmo desafio com o qual Kant se deparou ao ter de esclarecer o modo pelo qual o sujeito moral põe para si a lei com a qual deve agir em concordância, ou seja, a indagação sobre a genealogia do dever. Obviamente, a resposta de Levinas não é kantiana. Não se trata de uma obediência que começa em mim mesmo, mas heterônoma. No entanto, é preciso frisar que, ao estruturar a subjetividade como substituição, rompe-se com a falsa oposição entre liberdade e não liberdade.

\begin{abstract}
A subjetividade é primeiramente substituição, oferta no lugar de um outro (e não uma vítima oferecendo-se ela mesma em seu lugar - o que suporia uma região reservada de vontade subjetiva por trás da subjetividade da substituição), mas antes da distinção entre a liberdade e a não-liberdade: não-lugar em que a inspiração pelo outro é também expiação pelo outro [...] (AE, p. 185, tradução nossa).
\end{abstract}

Aqui temos uma ambiguidade propositalmente criada por Levinas para que seja possível a estranha reversão da passividade em atividade ${ }^{8}$ e a conciliação da heteronomia com a autonomia, ou seja, "a possibilidade de encontrar, anacronicamente, a ordem na própria obediência e de receber a ordem a partir de si mesmo" (AE, p. 189, tradução nossa). Ser estruturado como substituição é ser refém. Mas não aquele que é violentamente submetido a essa condição. Ser refém é ser inevitavelmente inscrito pela alteridade, que se faz presente na minha palavra independentemente da minha vontade. O resultado que temos é uma liberdade perpassada pela responsabilidade por outrem, anterior a qualquer iniciativa, visto que é impossível evadir-se da alteridade. Responsabilidade e liberdade devem ser vistas como uma unidade. Enquanto sou individuado pela inspiração ética da responsabilidade pelo outro, a liberdade é a possibilidade de exercer essa responsabilidade mesma que me foi heteronomamente inspirada.

\title{
APONTAMENTOS FINAIS
}

No desenrolar de nossa exposição, a pergunta que intitula nosso artigo - "como pensar a liberdade a partir da substituição?" - foi decomposta em outras três: 1) por que Outramente que ser? 2) se não se trata mais de hospitalidade, o que significa substituição? e 3) em que

\footnotetext{
${ }^{8}$ Sobre essa relação entre atividade e passividade desde a perspectiva fenomenológica e da relação entre Husserl e Levinas, confira Fabri (2015).
} 
consiste a liberdade no contexto da substituição? Optando por essa estratégia expositiva, buscamos evidenciar que para fazer uma primeira aproximação ao problema da relação entre liberdade e substituição é fundamental ter em mente, pelo menos, três aspectos do pensamento levinasiano.

Os dois primeiros são de interesse histórico-conceitual e se desenvolveram desde uma confrontação entre a estrutura argumentativa de Totalidade e infinito e Outramente que ser, mediada pelo texto-chave de Derrida, Violência e metafísica - tomando como tese, evidentemente, que há um caminho a ser percorrido que vai do texto de 1961 ao de 1974. Dessa forma, buscamos defender que Outramente que ser representa uma superação metodológico-linguística. Considerando a razoabilidade dessa hipótese, prosseguimos demarcando como uma das diferenças mais fortes o modo como a subjetividade é pensada nos dois textos. Assim, confrontamos o conceito de hospitalidade com o de substituição.

O último questionamento foi de interesse exclusivamente conceitual e buscou problematizar a relação entre liberdade e substituição. Surgiu sobretudo da dificuldade gerada por Levinas ao caracterizar esta última como algo independente da vontade. $\mathrm{O}$ sujeito não escolhe substituir-se. Dessa forma, não há uma liberdade da vontade anterior e possibilitadora da substituição. Que sentido, então, teria em falarmos de liberdade? A noção fundamental à qual recorremos para buscar pensar a liberdade a partir da substituição foi a de inspiração, de modo que poderíamos falar que em Levinas temos uma liberdade inspirada. Evidentemente Levinas não utiliza o termo inspiração para adjetivar a liberdade. Trata-se de uma escolha interpretativa que fizemos para sublinhar a importância que há em pensar conjuntamente liberdade e inspiração em Outramente que ser.

Gostaríamos de concluir com uma sugestão. É recorrente considerar que a primazia que a responsabilidade tem em Levinas dá ao conceito de liberdade uma função secundária, quase sem importância para compreendê-lo. As dificuldades geradas por essa primazia da responsabilidade também são gigantescas se pensarmos que o que é tido como usual é considerar que apenas se pode falar em responsabilidade se houver uma liberdade que a possibilita, ou seja, só pode ser responsável quem é livre. Acreditamos que a proposta de Levinas não é uma mera inversão dessa relação. Tal relação não deve ser compreendida em termos de uma oposição cuja função é estabelecer a anterioridade ou primazia da responsabilidade ou da liberdade. Assim, não é a responsabilidade que condiciona a liberdade ou contrário, mas ambos os conceitos devem ser pensados como uma unidade: a possibilidade de fazer o que nenhum outro poderia. Obviamente, a brevidade das nossas considerações 
ainda deixa muitas questões em aberto, mas acreditamos ter cumprido o objetivo deste artigo se, sistematizando a configuração desse problema em linhas gerais e com clareza satisfatória, atrairmos o interesse do leitor para essas questões.

\section{REFERÊNCIAS}

AGUIAR, Diogo Villas Bôas. O paradoxo levinasiano de uma liberdade heteronômica. 2014. 82f. Dissertação (Mestrado em Filosofia) - Departamento de Filosofia, UFPE, Recife, 2014.

ATTERTON, Peter. From Transcendental Freedom to the Other: Levinas and Kant. In: NEW, Melvin (Org.). In proximity: Emmanuel Levinas and the $18^{\text {th }}$ century. Texas: Texas Tech University Press, 2001, p. 327-354.

BECKERT, C. A túnica de Nesso ou a subjectividade impossível. In: BECKER, C. (Org.). Levinas entre nós. Braga: Centro de filosofia da Universidade de Lisboa, 2006, p. 103-112.

BERNASCONI, R. What is the question to which 'substitution' is the answer? In: CRITCHLEY, S.; BERNASCONI, R. (Org.). The Cambridge Companion to Levinas. Cambridge: Cambridge University Press, 2006, p. 234-251.

CALIN, R. Levinas et l'exception du soi. Paris: PUF, 2005.

CHALIER, C. Lévinas: a utopia do humano. Lisboa: Instituto Piaget, 1996.

DERRIDA, J. Violência e metafísica. In: DERRIDA, J. A escritura e a diferença. São Paulo: Perspectiva, 2011.

FABRI, M. O sujeito moral entre passividade e atividade: Husserl, Levinas e a afecção pelo valor. Revista Ipseitas, v. 1, n. 1, p. 106-118, jan./jun. 2015.

FABRI, M. Modalidades psíquicas irredutíveis: Levinas e a negação originária. Revista de filosofia Aurora, v. 22, n. 31, p. 409-422, jul./dez. 2010.

LEVINAS, E. Autrement qu'être ou au-delà de l'essence. Dordrecht: Kluwer Academic Publishers, 1991.

LEVINAS, E. Totalidade e infinito. Lisboa: Edições 70, 2008.

MALONEY, P. Levinas, substitution, and transcendental subjectivity. Man and World, Netherlands, v. 30, p. 49-64, 1997.

PÉREZ, José Luis. Difícil humanidade. Em torno do conceito levinasiano de liberdade. In: BECKERT, C. (Org.). Lévinas entre nós. Lisboa: Centro de Filosofia da Universidade de Lisboa, 2006, p. 123-139. 